\title{
Value of communication as an integral feature of a modern society and a condition for its sustainable development
}

\author{
Elena Shakirova*, Anna Reznikova, and Andrey Guskov \\ The Don State Technical University, 344003, Rostov-on-Don, Russia
}

\begin{abstract}
The relevance of our research is due to the processes taking place in a modern Russian society. Value orientation is the most important component of a human life, the basis for the life goals formation and, as a result, it acts as a motivation encouraging a person to behave according to his expectations. The values of a person of each epoch differ from each other as the external environment influences each of us including our spiritual world. Interpersonal communication and communication through various technological means is of great importance to a modern society. It is difficult for modern people to imagine themselves without a cellphone with dozens of apps installed and connected to the Internet. And this digital approach changes even the attitude towards a communication value, reconsiders it. The authors attempted to define a phenomenon of a communication value, classify the communication processes in a modern society, describe an impact of the communication processes within its value into an individual and explain a process of a revaluing under certain circumstances taking in account fundamental factors for the sustainable development of the world.
\end{abstract}

\section{Introduction}

The essence of a man and the meaning of his existence, purpose and mission have long been taken as one of the main issues of philosophy. What motivates a person to perform certain actions? The question has agitated the minds of thinkers for thousands of years. The value orientations of the individual play a dominant role in the questions of the humanities aimed at studying the individual. Values are the main basis of spiritual, cultural, and under modern circumstances, material development of a person and society [1,2].

The relevance of the topic is due to the processes taking place in a modern Russian society. People are the subject of a constant stress, constant changes of a political and economic nature. Modern realities do not give a person any guarantees, that causes uncertainty of views, motives and actions. It is impossible to ignore and not mention the main source of destabilization of the situation around the world - the coronavirus pandemic that not only had a poor impact on the economic development of all countries, but also aggravated discontent and segmentation in society [3].

\footnotetext{
* Corresponding author: chakirova31997@ mail.ru
} 
The wave of transformations that engulfs a society also causes various changes in the person himself. These are, in particular, changes in the spiritual nature, the deformation of moral guidelines and norms, and, as a result, the loss of the highest values that make up the meaning of a being. In connection with the transformation of previous stereotypes and principles, it is necessary to restore spiritual guidelines by acquiring new ideals and values, and to form a new value worldview $[4,5]$.

A person of the digital age lives in the space of communication, which is woven from images, messages, symbols, myths and stereotypes. Forming a generalized concept of communication from the point of view of the communication theory, we can say that communication is the process of transmitting, exchanging information. From the philosophic point of view, this concept is not limited only by the information messages exchange. Communication can be made up of economic exchanges (J. Baudrillard), the translation of myths (K. Baudrillard, Levi-Strauss, R. Barth), an exchange of views in a street scene (E. Giddens), a dialogue between two (M. Buber), dead monuments and cultural texts (Yu. Lotman) [6].

One of the main distinguishing features of modernity is the creation of a global information space, the transition of the concept of "information" into the economic system and the rapid development of the technological sphere.

\section{Materials and methods}

The methodological basis of the article is the work of modern researchers in the field of media philosophy in general and axiology in particular. The work was also influenced by a number of Russian authors in the field of marketing and advertising, as well as by the fundamental sociology of M. Weber and other scientists.

In the process of writing the scientific work the authors used:

- comparative and empirical methods of information retrieval that helped the authors to retrieve the necessary amount of data concerning the issue under discussion,

- a systematic approach that gives a careful analysis of the existing sociocultural interactions, - methods of analysis and synthesis aim at denoting values as a part of sociocultural reality and defining them as a significant part of the modern society,

- method of induction and deduction.

\section{Results}

Researchers of modern communication processes speculate about the virtualization of semiotic cognition[7] The iconic conceptual apparatus of a modern man has undergone global changes. In the old days, people formed symbolic signs in their consciousness based on independent conclusions made in the process of obtaining direct experience and analyzing the situation. In this case, the distortion of the content of the value was almost impossible. However, with the gradual virtualization, people began to master reality with the help of mass media, without their own participation in the process of cognition. It has created a greater opportunity to manipulate and control people than before, because a person without his own experience is more likely to learn incorrect symbolic meanings, and will act according to the prescribed algorithm to the detriment of himself. In the process of writing the scientific work, comparative and empirical methods of information retrieval, a systematic approach, methods of synthesis and analysis, induction and deduction were used [8].

Modern society, its life activity, functioning is impossible to imagine without a large number of social connections, a huge flow of information (and information noise), which form the spiritual and material component of our life. The current world is characterized by 
globalization and universal integration within the framework of economic activity, but fragmentation in the political and cultural spheres. Today, communication is recognized as an essential and socially significant component of social life. It is important in such conditions to choose the right channels and means of communication, the content of the information message.

\section{Discussion}

The philosophical category of a "value" is universal. This definition was established in philosophy as an independent conceptual unit in the 60s of the XIX century. It is customary to identify this process with the treatise of the German philosopher G. Lotze "Foundations of practical Philosophy" and with his work "Microcosm"[9]. In his opinion, it is necessary to clearly distinguish between the world of phenomena and the world of internal values. Good, for example, cannot be included in the circle of natural phenomena. In the role of the abode of values is the "kingdom of goals". The world of values has not just a real existence as something due, but is "the most real of all things". Explaining the contrast between the world of facts and the world of values, he also pointed to the intrinsic value of things, which is manifested through the ability of a person to feel. His merit is in raising (and not solving) the question of the correlation of the objective and the subjective in values, and most importantlyin raising the concept of "value" in the circle of the main categories of philosophy $[10,11]$.

After the definition of a value as a categorical concept, an axiology - the philosophy of value was formed. Its formation is associated with neo-Kantianism, especially with the name of V. Windelband. He emphasized that G. Lotze had advanced the concept of value and placed it at the head of metaphysics. On this basis, according to V. Windelband, the theory of value arises "as a new type of philosophical basic science". Value, he writes, presupposes universal obligation and consists in universal mandatory recognition. This normative obligation of value has its supernatural foundation: "The highest values of the experiential life-knowledge, morality, and art-become the living acts of the Deity in man and acquire a higher and deeper meaning in the transcendental consciousness"[12]. The task of philosophy, points out Windelband is to comprehend "universal values", which form the general plan of all the functions of culture and the basis of every individual realization of value. But even these values could be described and explained only for the purpose of giving an account of their meaning; it treats them not as facts, but as norms. Before axiology acquired its modern features, it went through a historical path of development equal to the formation of the philosophy itself, within the framework of which it was formed. In ancient and later medieval philosophy, values were identified with being itself, and value characteristics were included in its concept. Values, therefore, were not separated from being, but were regarded as being in being itself. For example, for Socrates and Plato, such values as good and justice were the main criteria of true existence. In addition, in ancient philosophy, an attempt was made to classify values. Aristotle distinguished self-sufficient values, or "self-values", to which he referred a person, happiness, justice, and values of a relative nature, the comprehension of which depends on the wisdom of a person.

A value is one of the main conceptual definitions in the system of philosophical and humanitarian discourses. It has several meanings and is considered as: the positive or negative significance of an object or phenomenon of reality (objective values); the normative (evaluative) side of the phenomena of public consciousness (subjective values). "The term 'value' is used to refer to the human, social and cultural significance of certain objects and phenomena, while referring, on the one hand, to the world of due, purpose, semantic basis, on the other - to the main category of political economy - value." In many sources, values are considered as meaning-forming factors of human life, contributing to human development, setting motivation in a particular type of activity $[13,14]$. 
As we mentioned above a concept of a value is a multidisciplinary term so it is applied towards educational paradigm as well. It is rather important for us to point out the system of values existing within a group of people having become our focus group aged 18-34 and this information is given in the following survey of the VCIOM Russian Public Opinion Centre (2017).

According to the survey, in the hierarchy of values of modern Russian youth (in the group from 18 to 34 years old), the first three places are occupied by income, order and stability, and self-realization [15]. The percentage of values is shown in Table 1.

Table 1. Hierarchy of values of Russian youth

\begin{tabular}{|c|c|c|}
\hline Place & Value & Percentage of respondents \\
\hline 1 & Income & $15 \%$ \\
\hline 2 & Order and stability & $11 \%$ \\
\hline 3 & Self-realization & $8 \%$ \\
\hline
\end{tabular}

The life of a modern person is impossible without the implementation of constant communication processes. Even Aristotle formed the simplest, later became the basic, model of communication. In this model, three main components of the communication process were presented: "speaker-speech-audience". The modern interpretation of this model is "communicator-message-communicant".

From the point of view of philosophy, communication is one of the attributive properties of matter. These properties are primarily due to strong relationships, relationships between phenomena and processes, resulting from the unity of the world.

If we turn directly to axiology, then from this point of view, any communication activity of individuals is the result of a thought process and goal-setting, that is, it has a directed character, has a goal and value orientations. However, it is important to note that this process can take place both consciously and unconsciously. This confirms the possibility of the influence of the means of communication on the subconscious and consciousness of a person, the possibility of distortion of his personal perception of information.

Is the process of communication and the means of communication itself a value? If we consider in this case the concept of value from the point of view of the layman, that is, something that carries an immediate value of some kind. Man is a social being who is not capable of being alone all the time. And if communication with your own kind is a vital necessity, then what is the situation with the means of communication? Modern people experience a sense of anxiety and stress when they can not access their gadget, public and social networks. In this case, indeed, for a particular individual, all this can be considered valuable, but in the global sense, it is only means and ways of interacting with the external environment - methods of entering into the communication process.

Taking into account all of the above, we can say that mass communication is in some way the identification of an individual with a certain group of society, the adoption of the values of this group, its worldview. Mass communication differentiates people into certain groups according to various characteristics, often these characteristics are associated with the sphere of interests or professional activity of a person.

The definition of "media" has firmly entered the conceptual apparatus of a modern man. The original formulation of media assumed that media is a means of communication that is perceived only by one sense organ. Media can include books, newspapers, paintings, music, and so on. In turn, multimedia is a means of communication that affects several senses simultaneously. The classic multimedia means are television and the Internet.

Media technologies are capable of reproducing social reality. A person may never visit other cities, but not only know about their existence, but also have a complete idea of what they look like [16]. 
World informatization has an impact on all spheres of modern life. Media technologies of interviews provide information, the rating of which is able to form a person's ideas about the world, society, and himself, and therefore have an impact on the worldview of the individual.

Communication becomes a powerful factor influencing the formation of human values, they affect both individual and collective values. Every day, by broadcasting to society examples of a beautiful and successful life, which is mostly identified with the concept of a "rich life", the means of communication influence our value orientations. They, together with the culture, the peculiarities of the mentality and the way of life of a particular individual, form the values, the attitude of the individual to the world around him and to himself. Which, in turn, are the core of a person's motivational system. Based on the goals, a person tries to form his social circle, evaluate reality and make decisions in a specific period of time, which determine the professional and personal activities of the individual.

Information affects a person's consciousness not only from a positive, but also from a negative side. The information society of the XXI century is filled with technologies aimed at managing and manipulating society in different aspects[17].

The systematic and prolonged influence of technological means on the specifics of the perception of the world picture by a person leads to a distortion of a value system. This is primarily due to the fact that the individual perceives those values, those concepts that are not based on personal experience and analysis, but are only the results broadcast in society, primarily by the mass media. A specific system of values is built up, an imaginary picture of the world, a refracted reality, is formed in the consciousness of a person. The complex of human values in this case is formed not as a result of analyzing the situation, personal and historical experience, not from communication with other people, but artificially, based on information messages from outside.

The duality of the current situation in the field of communications in the modern world lies primarily in the fact that the means of information dissemination have long gone beyond their own functions, the main of which is primarily information. The transmitted information has a profound influence on the formation of the system of the inner world of the individual, its psychological state, and often have a detrimental effect on the system of human values. While some researchers enthusiastically list the richness of the methods of mass communication, considering them as completely new, characteristic only for the XXI century phenomena, others look at the current phenomena with caution, expressing the opinion that exaggerated attention to a number of positive trends in the development of mass communication leads to an underestimation of the role of the manipulative factor in the structure of communications. Some people are so immersed in the world of virtuality that they lose the need for real communication, the person closes in himself, becomes vulnerable to external stimuli. And indeed, many contemporaries would rather part with someone from their loved ones than say goodbye to their smartphone, which already has their whole life [18].

Mass communication media are directly involved in the formation of value orientations, broadcasting certain values - they demonstrate to a person the life to which he should strive. Most often, the media turn to family and professional values, extol happiness, health, freedom, creativity, love, faith, etc. However, it should be noted that in modern realities, these values are often transferred to the material plane, where the level of wealth is the determining criterion by which you can say whether you have achieved certain values, whether you have certain benefits. The usual concept of value is distorted.

Communication forms a person's view of the world around him. A human mind is designed to remember negative phenomena easier and negative facts and news discussed by all the media assist in it. There is much more information with a negative connotation than there is positive news. A striking example of this phenomenon is the situation with the new 
coronavirus infection COVID-19, news kept people in a constant fear and tension for a long period of time. Until the society is simply fed up with being afraid, many media have even made a special option to disable news about a viral infection. A frightened society, living in the rhythm of endless changes, political and economic instability, simply cannot have any stable values.

A communication hunger stroke a global society during a pandemic lockdown. The situation with a lack of communication influenced almost all the spheres of everyday life and illustrated an importance of communication in our life. The most influenced sphere, as it turned out, was an educational sphere. Both teachers and students were tightened up under the circumstances of live communication absence: it was a hard time for the teachers in the framework of motivating students to some new achievements because lack of communication brought another serious problem such as lack of competitiveness normal for a classroom activity but odd for online study.

It became obvious that a mankind is not ready to give up a live communication and turn to a total digitalization.

And another important concern within a pandemic lockdown was a revalue of a communication activity. As it was inaccessible it was utmost desirable. It was a real communication hunger for live meeting with friends, relatives with different activities performance; it was a practical example of revaluing some routine activity that we got used to.

The pandemic period gave us an opportunity to rethink, revalue our attitudes towards people around and even to work out some complex of measures of socializing people back after a long period of a lockdown. [3] A person does not know what he wants, what is good for him, he is constantly in sight and under the influence of a huge number of external factors. In such conditions, the old values "break", and the new ones acquire an unknown and indistinct character. The old names remain, but the meaning of the values is fundamentally changed.

Many modern sources of information reinforce the segmentation of society, create false ideals and role models. In many scientific publications on communication, media, etc., it is stated about the humanization and individualization of the means of communication. But at the same time, society is simply torn from beautiful "pictures" that extol wealth and a "wellfed" life. We are constantly told: "Live for today!" But it is not always about using opportunities, resources and enjoying every day of your life, it is often about impulsiveness and thoughtlessness of chaotic actions [19].

Social networks show us examples of happy calculation, lack of education, stupidity turns into humor. We all live daily in a world of information mirages, which is filled with pseudovalues. Stephen Covey wrote "To Be but not to Seem" [20]. A modern man, and especially the younger generation, lives in a world where it is much more important to seem and not to be.

Future specialists in the media professions are taught from the first lessons to direct the information at the low-educated representatives of the target audience, so that everyone else will surely understand the message. However, why equalization always occurs is relative to ignorance. Why can't we strive at least for the "golden mean", because we want to believe that the majority still has a sufficient level of knowledge and perception of information. Thus, the media equalize everyone to a low level and do not try to promote the development of society [21].

Values are what motivates each person. They form the idea and personal "philosophy" of each person. On the basis of the system of values, a person sets goals and super-goals for life that will contribute to the development or degradation of the individual, in many cases can determine the line of behavior of a person, his professional and personal life. In the center of the perception of modern man were such values as wealth and prosperity, as well as the 
individual trajectory of personal development. It is amazing how the information space combines the ideas of absolute stupidity, easy life and endless entertainment, with the ideas of the need for constant self-development and self-improvement, the ideas of the need for continuous education throughout a lifetime.

The current trend in the field of values, especially among young people, is individualization. Modern man puts his personal goals above public ones, in many cases this happens despite possible discrepancies with generally accepted moral norms. For a modern young person, freedom of action and opinion, the realization of his personal rights and freedoms are of great importance. But not everyone understands that your personal freedom should end where the other person's personal space begins. The line between freedom and permissiveness is becoming less and less visible. For many, self-realization becomes a supergoal, a super-value. All these aspects contribute to the formation of the uniqueness of each person. However, it also contributes to a disregard for moral values, for the law, and for one's own duties. Above all, there is a sense of personal comfort, pleasure, achievements and victories. The dangers of individualization are that it can turn into a banal selfishness.

Despite the development and external indicative independence, modern young people have become more vulnerable to the imposition of ideas and information. Yes, they trust adults less and for them there are often no absolute authorities, but at the same time, with a competent selection of means of conveying an information message through clear and simple mechanisms for them, they are easily manipulated and believe in distorted messages.

The concept of the philosophy of communication should be firmly embedded in our life, so that science can once again address the problems of not only the global world, but also each individual person. These values, formed primarily in the modern youth environment, can not be clearly perceived as something good or bad, they are rather neutral in nature. With the right perception, the right presentation of information reasons, they can all become the strongest motivator for truly positive and reasonable changes in society [22,23]. In particular, the development of personal qualities, their own potential for further activities for the common good, the formation of a sense of importance for the whole world, a sense of strength and opportunities to change life for the better with your personal contribution, a focus on the transfer of cultural heritage, knowledge and experience. Philosophy should promote selfunderstanding of the personality of their inner world, help people develop their critical thinking, to be able to independently analyze and draw conclusions from the information received, so that people learn to hear themselves and understand each other, and not blindly believe in conjured images.

\section{Conclusions}

Society is always in a state of renewal, every day new knowledge and discoveries of various scales appear, we are immersed in new problem situations, we get out of them, and everything is again in a circle. These are the conditions for the existence of a man and his culture. Changing value systems is a natural and inevitable process, not always amenable to the laws of logic.

The formation of a system of values is impossible in the modern world without the use of means of communication - the delivery of information. Communication as it is, communication with other individuals and the outside world is the most important modern value. We must not forget that the ideas of modern society about the world are mostly formed under the influence of the means of communication. For a huge part of the audience reality is not the event but its interpretation and sometimes its transformation.

We strongly believe that a communication value wouldn't be reconsidered in the framework of a modern digital epoch as we absolutely sure that only a balanced 
communicative sphere could help a mankind to achieve a sustainable development of a society.

\section{References}

1. L. Stapleton, D. Marques, IFAC-PapersOnLine, 49 (29), 283 (2016)

2. C. Milchram, C. Märker, J.-F. Hake, Energy Procedia, 158, 3741 (2019)

3. A. Reznikova, T. Kudinova, R. Patuykova, N. Olomskaya, O. Dyshekova, E3S Web of Conferences 210, 18037 (2020)

4. T. Olenich, A. Mekushkin, N. Mamchits, N. Ugrekhelidze, E3S Web of Conferences 175, $15032(2020)$

5. J. H. Spangenberg, J. Settelea, Ecosystem Services 18, 100 (2016)

6. A. Nazarchuk, Questions of philosophy

http://vphil.ru/index.php?option=com_frontpage \&Itemid=1

7. N.I. Morozova, O.S.Buryakova, N.Z. Aliyeva, E.B.Ivushkina Lecture Notes in Networks and Systems (2019) https://www.scopus.com/inward/record.url?eid=2-s2.085063216103\&partnerID=40\&md5=536925d2b834f568a3b48ff633cde1eb

8. A Mokina, L. Khoronko, E3S Web of Conferences 175, 15008 (2020)

9. R. Hermann, L. Mikrokosm Thoughts on the natural and everyday history of mankind, the experience of anthropology, the soul (URSS: Librocom, 2012)

10. M. Dresow, Studies in History and Philosophy of Science Part A. 82, 57 (2020)

11. K.Vaesena, J.Katzav, Studies in History and Philosophy of Science Part A 78, 73 (2019)

12. V. Windelband, Preludes. Philosophical articles and speeches (Hyperborea: Kuchkovo Field, 2011)

13. I. Abakumova, A. Berberyan, H. Berberyan, International Journal of Cognitive Research in Science, Engineering and Education. 7(2), 11 (2019)

14. D. Steel, Ch. Gonnerman, M. O'Rourke, Studies in History and Philosophy of Science Part A. 63, 22 (2017)

15. VCIOM Russian Public Opinion Centre https://www.wciom.com/index.php

16. Y. Leea, J. Kim, Public Relations Review. 47(1) (2021)

17. A. Zhdanko Identification of cognitive manipulations that have the greatest impact on students in the internet (2019)

18. T. A. Shiryaeva, A A. Arakelova, E.V. Tikhonova, N. M.Mekeko, Heliyon 6, 12 (2020),

19. M. Goyanesab, P. Borahc, H. de Zúñigabde, Computers in Human Behavior, 120 (2021)

20. Covey Stephen Primary Greatness: The 12 Levers of Success Simon \& Schuster (2015)

21. U. Milhaleva, Innovation in education: problems and ways of their solution E3S Web of Conferences 210, 18037 (2020)

22. A. McClelland, D. Peel, C-M.L. Hayes, I.Montgomery Town Plan. 84: 583 (2013)

23. I. Zyubina, A. Dzyubenko, G. Matveeva, A. Ratokhina, G. Ostrikova, SGEM Bulgaria, 1089 (2017) 